\title{
Análise da utilização do brinquedo terapêutico em crianças de 03 á 12 anos hospitalizadas
}

\author{
Analysis of the use of therapeutic toys in children from 3 to 12 years hospitalized \\ Análisis del uso de juguetes terapéuticos en niños de 3 a 12 años hospitalizados
}

\begin{abstract}
RESUMO
Objetivo: Analisar a prática de atividades com brinquedo terapêutico com crianças hospitalizadas ou em tratamento ambulatorial antes do procedimento invasivo. Metodologia: Trata-se de uma pesquisa de campo, caráter qualitativo transversal, analisando o sentimento das crianças com uso do brinquedo terapêutico. Foram acompanhadas 6 crianças, de 03 a 12 anos em tratamento ambulatorial e internadas no setor de oncologia num hospital pediátrico de grande porte em Vitória, durante 14 dias, sendo aplicado em crianças em tratamento oncológico com até 3 meses de início de tratamento. Sendo observado durante os procedimentos com as crianças suas reações antes e após o uso do brinquedo terapêutico, e registrados em diários de bordo. Quanto aos procedimentos, o trabalho de pesquisa foi experimental, tendo o boneco como agente facilitador do processo, e introduzido na rotina. Resultados: 0 procedimento foi realizado junto com o enfermeiro da instituição de saúde, devido ao maior contato que ele tem com a criança e a sua família, facilitando o entendimento da criança. Todos gostaram de vivenciar essa nova experiência. Conclusão: Concluiu-se ao usar o brinquedo terapêutico antes os procedimentos invasivos contribuíram para um melhor entendimento das crianças sobre os procedimentos que iriam ser submetidas, deixando-as mais calmas e seguras. DESCRITORES: Brinquedo Terapêutico; Crianças; Procedimentos Invasivos.
\end{abstract}

\section{ABSTRACT}

Objective: To analyze the practice of activities with therapeutic toys with children hospitalized or undergoing outpatient treatment before the invasive procedure. Methodology: This is a field research, with a cross-sectional qualitative character, analyzing the feelings of children using therapeutic toys. Six children were followed, from 03 to 12 years old in outpatient treatment and admitted to the oncology sector in a large pediatric hospital in Vitória, for 14 days, being applied to children undergoing cancer treatment with up to 3 months of treatment initiation. During the procedures with the children, their reactions were observed before and after the use of the therapeutic toy and recorded in logbooks. As for the procedures, the research work was experimental, with the doll as the facilitating agent of the process and introduced in the routine. Results: The procedure was performed together with the nurse at the health institution, due to the greater contact he has with the child and his family, facilitating the child's understanding. Everyone liked to experience this new experience. Conclusion: It was concluded when using the therapeutic toy before the invasive procedures contributed to a better understanding of the children about the procedures that would be submitted, leaving them calmer and safer.

DESCRIPTORS: Therapeutic Toy; Children; Invasive Procedures.

\section{RESUMEN}

Objetivo: Analizar la práctica de actividades con juguetes terapéuticos con niños hospitalizados o en tratamiento ambulatorio antes del procedimiento invasivo. Metodología: Se trata de una investigación de campo, de carácter cualitativo transversal, que analiza los sentimientos de los niños utilizando juguetes terapéuticos. Se siguió a seis niños, de 03 a 12 años en tratamiento ambulatorio e ingresados en el sector de oncología en un gran hospital pediátrico de Vitória, durante 14 días, aplicándose a niños en tratamiento oncológico con hasta 3 meses de inicio de tratamiento. Durante los procedimientos con los niños, se observaron sus reacciones antes y después del uso del juguete terapéutico y se registraron en los libros de registro. En cuanto a los procedimientos, el trabajo de investigación fue experimental, con el muñeco como agente facilitador del proceso, e introducido en la rutina. Resultados: El procedimiento se realizó en conjunto con la enfermera de la institución de salud, debido al mayor contacto que tiene con el niño y su familia, facilitando la comprensión del niño. A todos les gustó vivir esta nueva experiencia. Conclusión: Se concluyó que el uso del juguete terapéutico antes de los procedimientos invasivos contribuyó a una mejor comprensión de los niños sobre los procedimientos que serían sometidos, dejándolos más tranquilos y seguros.

DESCRIPTORES: Juguete Terapéutico; Niños; Procedimientos Invasivos.

RECEBIDO EM: 30/05/2020 APROVADO EM: 31/05/2020 


\section{Poliana Rosalém Francisco}

Enfermeira.

ORCID: 0000-0002-2759-7754

\section{Lívia Perasol Bedin}

Enfermeira.

ORCID: 0000-0001-8228-6468

\section{Claudia Curbani Vieira Manola}

Enfermeira. Mestre em Administração.

ORCID: 0000-0002-0925-4432

\section{Evandro Bernardino Mendes de Melo}

Enfermeiro. Mestre em Enfermagem. Universidade Federal do Espírito Santo.

ORCID: 0000-0002-1772-3083

\section{Priscilla Silva Machado}

Enfermeira. Doutora em Enfermagem. Mestre em Saúde Coletiva. Universidade Federal do Espirito Santo.

ORCID: 0000-0001-5134-2914

\section{Maristela Villarinho de Oliveira}

Enfermeira.

ORCID: 0000-0002-5265-9195

\section{INTRODUÇÂO}

A hospitalização de uma criança é algo que abala emocionalmente e estruturalmente toda família, pois é mudada toda a rotina. É potencialmente estressante para criança sendo percebida como algo que a priva de sua liberdade, autonomia, alterando sua rotina de estar junto com seus familiares, causando ansiedade, estresse, medo, angustias, insegurança, podendo ocasionar agravos emocionais, caso não se tenha uma assistência qualificada ${ }^{(1)}$.

A motivação da realização desse estudo é oferecer a criança uma assistência humanizada por meio do brinquedo terapêutico e, através do brinquedo, explicar o procedimento invasivo, garantindo a criança não só o cuidado físico. Adequando a comunicação para um melhor relacionamento interpessoal, criando vínculo entre paciente/família e equipe. Buscando técnicas para que a criança possa compreender o momento vivenciado, contribuindo para a diminuição de estresse e ansiedade, reduzindo os traumas que a hospitalização pode causar, através do brinquedo terapêutico.

A Política Nacional de Humanização do Ministério da Saúde, com objetivo de fortalecer assistência humanizada e mais qualifi- cada, vem aprimorando e criando técnicas práticas a fim de garantir ao usuário uma assistência mais humana e o brinquedo terapêutico vem como agente facilitador para contribuir com esse processo ${ }^{(2)}$.

O brincar favorece o fortalecimento do vínculo entre a família e paciente, pois os pais também estão fragilizados com a hospitalização, e necessitam ver seus filhos mais felizes. Quando as crianças brincam representam estarem melhor, dando maior confiança e esperança para os pais, os fortalecendo para que possam ser suporte para a criança ${ }^{(3)}$.

Durante a hospitalização, a criança fica no leito em grande parte do dia, sendo submetida aos procedimentos invasivos, restrita a brincar e aos seus hábitos rotineiros, alguns procedimentos dolorosos, tais como: agulhas, cortes, medicações, passagem e retiradas de sondas, muitas vezes sem serem orientadas adequadamente, de forma compreensível à sua idade sobre os procedimentos a serem executados, tornando-se passivas às imagens, associando cheiros, sons estranhos e cercada por pessoas desconhecidas, que não fazem parte a sua rotina diária, e associam a elas como os causadores desse sofrimento, tendo uma visão ruim do hospital e da equipe, deixan- do-as mais vulneráveis e com risco de danos psicológicos ${ }^{(4)}$.

Nessa perspectiva, a importância do brincar para o desenvolvimento da criança mostra-se fundamental, onde há diversas leis e organizações que defendem o direito de brincar, as colocando junto com os direitos de necessidades básicas como, alimentação, escola, saúde e outros ${ }^{(5)}$.

O brincar é algo natural na rotina da criança, assim, pode-se usar como estratégia para o cuidado, oferecendo uma assistência mais integral. No brincar, a criança desenvolve o neuropsicomotor e socializa, o uso do boneco, além de desenvolver esses lados, servirá para aliviar o estresse, o medo, a compreender o procedimento e a construir vínculo entre criança/família e equipe ${ }^{(6)}$.

Seguindo esse mesmo raciocínio, neste período de internação a criança é também submetida a procedimentos invasivos fundamentais para o tratamento e recuperação, porém, dolorosos deixando de lado as brincadeiras, sendo importante que a assistência dessa criança seja além dos cuidados físicos, que seja uma assistência acolhedora, que abranja todos os estados, físico, psicológico e emocional da criança, adequando as técnicas ${ }^{(1)}$.

No hospital pode-se ter a brincadei- 
ra recreacional com o intuito da criança relaxar, brincando espontaneamente, já com no brinquedo terapêutico, a brincadeira é direcionada por profissionais para promoção do bem-estar psicoemocional da criança, dando a ela a oportunidade e liberdade de expressar verbalmente ou não verbalmente seus anseios, medos. Sendo aplicado um brinquedo específico e com função estabelecida para cada necessidade. Podendo ser desenvolvido pela enfermagem uma vez que já há uma lei regulamentada pelo COREN, que recomenda a prática dessa técnica ${ }^{(7)}$.

O objetivo do presente estudo consiste em analisar a prática de atividades com brinquedo terapêutico com crianças hospitalizadas ou em tratamento ambulatorial em hospitais da grande Vitória. Os objetivos específicos são: levantar os métodos de aplicação de brinquedo terapêutico durante hospitalização ou tratamento em pediatria; vivenciar o uso dos brinquedos terapêuticos durante a realização dos procedimentos de enfermagem em crianças de 03 a 12 anos e descrever as respostas das crianças durante a utilização do brinquedo terapêutico por meio do diário de bordo.

A hospitalização de um indivíduo é algo que altera toda sua rotina de vida, de convivência familiar; em se tratando de uma criança, essas alterações poderão ser muito maiores, gerando estresse, medo, além do próprio adoecimento que está vivendo ${ }^{(8)}$.

É comum que surja a ansiedade antes ou durante o procedimento, ocasionando um grande desconforto para a criança, fazendo que ela desenvolva medo, receio em ir ao serviço de saúde, pode ocasionar insônia, pesadelos, traz danos também pela quebra da rotina e a separação desde ambiente familiar. A criança com esses traumas se tronará um adulto com medo de procurar cuidados médicos, que evitará ambientes hospitalares, trazendo sérios danos à saúde ${ }^{(9)}$.

Isto nos leva a refletir sobre a forma e atitudes que devemos ter com essa criança durante sua vivência hospitalar. $\mathrm{O}$ brinquedo terapêutico é uma das possibilidades de ajudar a criança a superar esse período crítico e doloroso para ela.
$\mathrm{O}$ brinquedo terapêutico oferece à criança um momento para liberar seus temores, medos, ansiedades, permitindo que expresse o que sente e o que pensa ${ }^{(8)}$.

Para autores ${ }^{(10: 1164)}$, “[...] o brinquedo terapêutico possui uma estrutura pré definida que usa o lúdico para redução de estresse e outros efeitos adversos que a hospitalização pode acarretar à criança hospitalizada".

O brinquedo terapêutico é uma brincadeira estruturada, que possui várias funções e finalidades, tais como: aliviar tensões, diminuir a ansiedade em decorrência dos procedimentos, orientar quanto aos procedimentos invasivos, fortalecer o vínculo da equipe de enfermagem com a criança. $\mathrm{O}$ brinquedo pode ser aplicado de três formas, cabendo à enfermeira que irá aplicar estabelecer qual será o mais apropriado naquele momento para a criança, a sessão deve durar de 15 a, no máximo, 45 minutos $^{(11,12)}$.

- Dramático ou Catártico Alívio, em que permite a criança a canalizar as suas emoções e necessidades. E que propicia à criança dramatizar experiências novas, difíceis de serem verbalizadas e, tornar-se emocionalmente segura;

- Instrucional ou preparatório: Tem a função de esclarecer, orientar sobre um evento que prepara a criança, por meio de uma brincadeira, para os procedimentos a que será submetida, a fim de promover sua compreensão sobre $o$ tratamento e esclarecer conceitos;

- Capacitador de funções fisiológicas: É aquele que ensina a criança a manusear equipamentos de funções fisiológicas, nos quais a mesma participa de atividades para melhorar seu estado físico, por intermédio de brincadeiras que reforçam e envolvem seu próprio cuidado.

A arte de brincar ajuda a criança no seu desenvolvimento motor, emocional, mental e social, e a falta das brincadeiras durante o período de internação poderá contribuir para a criança apresentar altera- ções psíquicas, apatia, alteração de humor e autoimagem prejudicada $^{(8-10)}$.

O brincar é tão necessário para uma criança que sua inibição constante na infância pode ser o indicador de neurose grave que, muitas vezes, pode ser ignorada, sendo vista como uma criança quieta ou tímida, mas na verdade o ato de não brincar mostra que pode estar sofrendo por algo ou alguém, criança sadia brinca, corre, se diverte. $\mathrm{O}$ uso do lúdico como agente facilitador nos adoecimentos promove o bem-estar psicofisiológico, podendo auxiliar a criança durante processos difíceis que ela esteja passando ${ }^{(13)}$.

Estudo refere que brincadeira é uma das principais linguagens na infância, e que é através dela que a criança dá significado e conhece o mundo, constituindo suas práticas culturais ${ }^{(14)}$.

Autores $^{(8)}$ citam o quanto doloroso é o processo de hospitalização, e que podem ocasionar transtornos e traumas às pessoas. Na infância esses transtornos são mais evidentes e mais intensos, podendo fazer que a criança fique mais agressiva, mais egocêntrica, mais egoísta devido ao tempo de hospitalização, podendo ser encarada pelas crianças como uma punição por algum comportamento inadequado ou desobediência.

$\mathrm{O}$ uso do brinquedo terapêutico em crianças hospitalizadas ou em tratamentos ambulatoriais poderá auxiliar no processo de internação, diminuição de traumas, medos, ansiedades, mas, é de extrema necessidade que a criança confie no ambiente, que tenha vínculo entre a equipe e a família, para que consiga brincar de forma prazerosa e criativa ${ }^{(15)}$.

O cuidado é um papel da enfermagem, e esse cuidado deve atender a todas as necessidades: as emocionais, as sociais e deve garantir técnicas adequadas para a comunicação e relacionamento interpessoal, o Brinquedo Terapêutico pode ser uma ferramenta para melhorar essa integração e garantir uma assistência integral e mais humanizada. Afirma-se, ainda, que é papel do enfermeiro cuidar do paciente integralmente, não só da sua patologia, mas também do aspecto emocional, social, in- 
terpessoal, visando o cuidado qualificado e humanizado buscando atender todas as particularidades para melhor assistência do mesmo ${ }^{(16)}$.

$\mathrm{O}$ processo de internação de uma criança é estressante, pois altera toda sua rotina, tendo hora para medicamentos, alimentação diferente, modificando seus hábitos diários; essas mudanças provocam na criança ansiedade, medo e o brinquedo terapêutico vem contribuir para aumentar e melhorar o vínculo entre os profissionais de saúde com ela e com sua família ${ }^{(17)}$.

Nesse sentido a pesquisa é relevante, pois cuidará integralmente da criança, qualificando a assistência e a deixando mais humanizada, minimizando os traumas que a hospitalização gera nas crianças e na família.

\section{METODOLOGIA}

Trata-se de uma pesquisa de abordagem qualitativa, pois permite compreender e vivenciar os momentos, os quais serão observados. A pesquisa qualitativa requer uma metodologia sensível às diferenças, aos acontecimentos, imprevistos às mudanças e às manifestações observáveis ${ }^{(18)}$.

Quanto aos procedimentos, o trabalho de pesquisa foi experimental, pois introduziu-se o boneco terapêutico na rotina da criança antes de um procedimento invasivo, tendo o boneco como facilitador do processo. E depois de realizado o procedimento, o boneco é retirado da criança.

O procedimento foi realizado junto com o enfermeiro da instituição de saúde, devido ao maior contato que ele tem com a criança e a sua família, tendo vínculos estabelecidos, facilitando o entendimento da criança.

O local para o desenvolvimento do estudo foi o Hospital Infantil Nossa Senhora das Graças, na grande Vitória, que atende crianças ambulatoriais, no setor da oncologia que farão procedimento invasivo. $\mathrm{O}$ setor escolhido foi o ambulatório de quimioterapia, que atende de segunda a sexta a partir das 7 h. As crianças chegam para quimioterapia diariamente as $7 \mathrm{~h}$ e entram para $\mathrm{o}$ atendimento que inicia por volta de $7 \mathrm{~h} 30$,
Quanto aos

procedimentos, o

trabalho de pesquisa

foi experimental,

pois introduziu-se o

boneco terapêutico

na rotina da

criança antes de

um procedimento

invasivo, tendo

o boneco como

facilitador do

processo. E depois

de realizado o

procedimento, $o$

boneco é retirado

da criança. ficam quase durante todo o dia, recebem alta e retornando no dia seguinte, então foi possível aplicar o brinquedo terapêutico no setor da internação oncológica.

A pesquisa foi desenvolvida durante $o$ período de 15 dias nas segundas, terças, quartas e quintas-feiras durante o mês de junho e julho no período da manhã, pois era o horário que as crianças entravam para iniciar o procedimento de quimioterapia.

Os sujeitos da pesquisa foram as crianças que estavam presentes no ambulatório de quimioterapia e na enfermaria oncológica com até 3 meses do início do tratamento. A idade das crianças variou de 03 a 12 anos.

A escolha das crianças que iriam participar da pesquisa foi realizada pelo assistente social juntamente com o enfermeiro, que iriam passar por algum procedimento invasivo, que possuíam condições físicas e mentais que viabilizassem sua participação no estudo e tivessem a aceitação do responsável, através da assinatura do Termo de Consentimento Livre e Esclarecido (TCLE).

Para este estudo foi utilizada a observação participante que é o tipo de procedimento que auxilia o pesquisador a conseguir informações sobre o sujeito da pesquisa e que não são acessíveis por meio de outros métodos, e que tem como objetivo analisar procedimentos fisiológicos e psicológicos, possibilitando a interação e a formação de vínculo entre o pesquisador e aos participantes, os deixando a vontade para expressar de maneira fidedigna suas experiências e sentimentos que poderiam não serem expostos sem essa integração ${ }^{(19)}$.

O diário de observação foi utilizado toda as vezes em que o brinquedo terapêutico foi empregado. A partir do momento em que a criança foi escolhida para participar da pesquisa o brinquedo terapêutico foi empregado antes de iniciar o procedimento na criança; primeiro foi realizado o procedimento na boneca, com auxílio da própria criança e, posteriormente, realizado o procedimento na criança.

Foram observadas 06 crianças, sendo acompanhada a rotina semanal de procedimentos. Sendo duas meninas de 9 anos de idade e quatro meninos com a faixa etária de 3 a 12 anos, as iniciais dos nomes fo- 
ram utilizadas nos resultados garantindo, assim, o anonimato. Observou-se, durante o estudo, as reações das crianças durante o período em que se encontravam com a boneca e depois durante o procedimento propriamente dito.

Este estudo foi aprovado pelo Comitê de Ética responsável pelas pesquisas da Católica de Vitória Centro Universitário com o n. ${ }^{0} 3.349 .300$.

Os dados foram coletados a partir de um instrumento de observação que foi único para cada criança. A criança era observada durante a realização da instalação da quimioterapia, isto é, durante a punção do Port a Cath (cateter totalmente implantável) ou PICC (Cateter central de inserção periférica), durante a realização de um curativo, e anotado em ficha própria seu comportamento.

O procedimento era realizado primeiro no boneco e mostrado à criança o que ia acontecer, depois o enfermeiro do setor iniciava o procedimento na criança. Neste momento, o pesquisador observava as reações na criança e no responsável. Estas crianças foram acompanhadas durante 3 sessóes.

\section{RESULTADOS E DISCUSSÃO}

Participaram do estudo seis crianças, duas meninas de 9 anos chamadas aqui pelas iniciais, a I.S.F com o diagnóstico de Leucemia LLA, que reside em Itarana-ES e R.V.S.M de 9 anos com o diagnóstico de Gânglioneuroblastoma reto-sacral e que reside no interior de Guriri-ES; e quatro meninos, dois de 3 anos sendo também referidos pelas iniciais, o A.M 3 anos, com o diagnóstico de Leucemia LLA, residente em Vila Velha-ES, H.C.O de 3 anos, com o diagnóstico de Astrocitoma Pilocítico residente no interior de Linhares, o M.P.P de 5 anos, com Leucemia LLA, que reside em Colatina, L.H.S.D de 12 anos, com Epidermólise Bolhosa, Síndrome de Down e Aplesia Heritoíde, reside na Grande Vitória-ES.

No diário de bordo foi possível identificar como a criança reage a um procedimento, sendo observado e analisado antes e após os bonecos. Na coleta pré bonecos foi identificado, por meio de informações colhidas com a mãe, que as crianças possuem diversas formas de expressar seus medos e anseios, conforme descrito abaixo.

A I.S.F ao ver a equipe de enfermagem demonstra medo com expressóes faciais assustadas, e durante algum procedimento ela grita, às vezes nem há procedimento invasivo, mas só o manipular já lhe é assustador. Mas ainda assim permite que seja realizado o procedimento.

A R.V.S.M, ao ver a equipe, olha assustada, mas não grita, chama a mãe e chora. Ela resiste um pouco, mas consegue fazer o procedimento.

O A.M. tem medo ao chegar na quimioterapia, pois sabe que terá que ser puncionado, permanece com expressão facial de angústia até virem realizar o procedimento. Apresenta resistência para realizar o procedimento, chora bastante segurando a mão da sua avó e pede para segurar a mão de alguém da equipe.

O H.C.O chega no ambulatório com expressão facial de choro. Sendo necessário que seja feito em duas pessoas o procedimento. Tem resistência à equipe e quem o manipula é só o enfermeiro.

M.P.P não demonstra medo da equipe de enfermagem, chora um pouco durante o procedimento, mas não apresenta muita resistência durante a realização.

L. H. S. D., é resistente à equipe e ao procedimento, fica com expressão facial irritada para a equipe e escolhe quem irá puncioná-lo, sendo necessário a presença do enfermeiro.

A partir destes dados, pode-se afirmar que a equipe deve conhecer a criança, mantendo-a o mais à vontade possível, pois ela já teve a ruptura de sua rotina em razão das suas internações, dos tratamentos longos, dos enfrentamentos de efeitos indesejáveis de medicações, a minimizar suas aflições anseios, sempre a escutá-la, valorizar sua opinião, tratar cada um com sua peculiaridade, pois ela faz parte do tratamento e também tem suas dúvidas, ela tem que estar a par do que vai acontecer para fazer parte do processo, esclarecer seus medos, para melhor adesão ao tratamento Gânglio neuroblastoma reto-sacral ${ }^{(20)}$.
Quando iniciou o uso do boneco, todos, crianças e acompanhantes, aceitaram sem resistência, como pode ser relatado por meio da fala dos acompanhantes:

\section{"Tudo que for pra ajudar é válido" (Mãe do L.H.S.D)}

\begin{abstract}
"Que bom que você está aqui e vai explicar o procedimento, é a primeira vez dela, hoje o médico conversou comigo, mas estou fora de órbita desde que ouvi a notícia, eu não ouvi só escutei até ele dizer que meu bebê tem câncer" (Mãe do R.V.S.M).
\end{abstract}

A educação em saúde é uma forma de diminuir a ansiedade causada pela hospitalização, bem como iniciar o processo de acolhimento e conhecimento entre os envolvidos. No diário pós-bonecos notou-se que houve uma melhora, tendo falas como:

\begin{abstract}
"Acho que ele gostou do boneco, gostou de interagir, hoje ficou mais calmo, foi um dos dias que ele ficou mais calmo" (Mãe do L.H.S.D.).
\end{abstract}

"Olha ele tá perguntando do procedimento, parece até que está entendendo!" (Mãe do M.P.P).

\begin{abstract}
"Que bom que você está olhando como uma criança, que brinca, $e$ não só um paciente com câncer, ele está com câncer, os profissionais daqui tem que olhar como uma criança, não com pena, pois espero conforto, para passar confiança a ele" (Avó do A.M).

"A I.S.F chora muito, na primeira aplicação do boneco ela chorou, mas gostou do boneco, nessa segunda vez nem acreditei que ela nem chorou!" (Mãe da I.S.F).
\end{abstract}

Ao aplicar na I.S.F, notou-se que a mãe era bem protetora, que queria até responder pela filha, alegando que ela era uma menina que não fala muito, que não interage muito com as pessoas, estava mais 
insegura que a criança quanto ao projeto do brinquedo. Mas quando foi mostrada a boneca e explicado como seria (trocar o curativo do PICC), nos paramentamos e fomos conversando, ela foi colaborativa, perguntou se iria doer, o porquê das luvas diferentes, ela relata que está com medo do cabelo cair, que está com saudade de casa. Ao realizar o procedimento ela chora e grita pedindo para parar que está doendo, ao acabar o procedimento conversamos, fazendo o combinado que no próximo faríamos de novo, e que teria que ser mais corajosa como a boneca. Na semana seguinte, fizemos o curativo novamente na boneca, ao fazermos nela (enfermeira da internação e eu) tivemos uma grata surpresa, fizemos o procedimento sem nenhuma intercorrência, ou manifestação de medo. O desconhecido gera medo, com uma explicação detalhada e ao colocar a criança para realizar o procedimento, mostrou uma notável melhora.

Ao aplicar a boneca na R.V.S.M, percebi o que era a princesinha da casa, que mesmo com sua falinha mansa e infantilizada o quanto estava assustada com as mudanças de seu cotidiano, ainda mais pelo despreparo e insegurança da mãe (uma senhora de 61 anos que engravidou aos 52 anos, gravidez gemelar bivitelinos). Colocamos a boneca deitada, nos paramentamos com luvas para avaliar as veias e fomos conversando como seria a punção e o porquê teríamos que "furar" o braço da boneca. Ela foi bem colaborativa, na hora que o procedimento foi feito nela, ela chorou, mas sem resistência à equipe, sendo satisfatória a reação dela comparada a do dia anterior.

O A.M é uma criança com 3 aninhos que parece ser um rapazinho, ele tenta reprimir seus sentimentos, até ao chorar. Acompanhei durante a punção, fizemos no boneco, ele no início ficou assustado com o dispositivo intra venoso, depois mostrei que se tira a agulha, que o que fica é molinho, ele pegou o plástico olhou, olhou, no procedimento chorou, pediu para segurar a mão, mas não resistiu à equipe e nem ao procedimento. No outro dia, ele veio para fazer a quimioterapia intraóssea na coluna vertebral. Conversamos que ele iria dormir, que quando acordasse teria um curativo no meio das costas, fizemos o curativo no boneco que ele nomeou de Guigui, quando a médica chegou para o procedimento ele olhou meio assustado pediu pra segurar a mão da avó e a do boneco e logo dormiu ao aplicar o sedativo.

O H.C.O se mostrou bem curioso, foi ao ambulatório para fazer a quimioterapia através do Port-a-Cath, estava visivelmente apreensivo, mas ao ver o boneco interagiu bem com ele, expliquei o procedimento, ele olhava atento, depois quando o enfermeiro veio para aplicar, ele chorou, mas não resistiu, ficando mais calmo segundo sua mãe. Me perguntou se o Teco (nome que ele deu ao boneco) chorou, disse que ele chorou um pouquinho, mas que ele fica bem paradinho para que não precise de mais pessoas o segurando para fazer o procedimento, porque quando o Teco não se mexia ele viu que acabava rápido. H.C.O quis conhecer a outra boneca, que a nomeou de Rebeca, nome da amiguinha da creche, ele brincou com os dois, os colocou de castigo, quando perguntei o porquê o Teco estava de castigo ele contou que foi porque Teco chorou, e depois lanchou com eles. Quando acabaram de lanchar (a criança e os bonecos) eu perguntei à mãe se ela achou que ele compreendeu que o boneco o representava e ela perguntou à criança sobre o procedimento e ele mostrou no boneco, além dela relatar que ele ficou mais tranquilo, visto que das últimas vezes era necessário mais de uma pessoa para fazer o procedimento.

O M.P.P na aplicação do boneco interagiu muito bem, colocamos a luva para fazermos a punção, fizemos a punção no boneco depois ocluímos, falei que antes de aplicar a quimioterapia tínhamos que lavar com soro, ele questionou deixando sua mãe surpresa, com as perguntas, perguntou se iria doer, como se lavava com soro, falei que algumas crianças sentem um choquinho, outras que dizem que sentem um geladinho, pedi permissão para que a enfermeira colocasse e ele deu o bracinho, quando aplicou o soro ele falou ai tia nem dói, só ficou geladinho e sorriu.
O L.H.S.D. chegou no ambulatório mal-humorado, expliquei o projeto à mãe (a que diz tudo que é para ajudar é válido), mas que ele não gosta de interagir muito não, ela relata que o filho que escolhe quem fará o procedimento, só permite que os enfermeiros o puncionem. Ao chegar perto dele, percebo ele receoso, mas colaborativo, largou o celular para me ouvir, digo que ele terá que ser puncionado para transfundir sangue, demonstro no boneco ele fica atento, me auxilia no procedimento. Ao terminarmos a punção no boneco, falo que agora faremos nele, ele olha faz com a cabeça que não, coloco o boneco ao lado dele (o boneco já puncionado) e ele mostra o local que prefere que o puncione, o enfermeiro chega para realizar o procedimento, ele ainda receoso mostra novamente o local, chora um pouco, mas fica calmo.

Ao analisar os diários de bordo das crianças, percebeu-se uma melhor manifestação ao procedimento, a criança fica mais calma ao saber exatamente como será o procedimento e com o boneco ela faz questionamentos para tentar entender, percebe que está sendo ouvida. Em crianças que não ficam internadas, só hospitalizadas para a quimioterapia, notou-se uma melhora do enfrentamento da rotina do tratamento, mas notou-se que teria a formação de um vínculo maior entre criança $\mathrm{e}$ boneco caso elas permanecessem cada um com o seu boneco.

$\mathrm{O}$ enfrentamento do diagnóstico de uma criança com câncer não é fácil, ver ela sendo submetida a diversos procedimentos invasivos, a reações indesejáveis do tratamento (como as náuseas, queda de cabelo, etc.) e perceber o medo só de chegar ao hospital, ou de ver alguém de branco, faz com que a perspectiva do tratamento se torne mais dolorida à família e à criança ${ }^{(21)}$.

A equipe de enfermagem é a que passa mais tempo com a criança e a família, ao usar o lúdico, fortalece o vínculo e, com isso, pode-se perceber e compreender os sentimentos e as necessidades da criança e sua família, esclarecendo as dúvidas, diminuindo a ansiedade e o medo que a hospitalização traz ${ }^{(11)}$. 
Para se estabelecer uma comunicação mais clara e humanizada, é valido que se use estratégias que ofereçam uma maior interação, como o brincar, trazendo o lúdico para melhorar a interação, uma vez que o universo de brincar já faz parte do cotidiano infantil.

\section{CONCLUSÃO}

O estudo permitiu que fossem conhecidos os métodos, os tipos de brinquedos terapêutico e sua aplicabilidade. Sendo escolhido o brinquedo instrucional, informando a criança o procedimento que será realizado no dia, pois a educação em saúde faz parte do processo de hospitalização, uma vez que o desconhecido gera medo e ansiedade. E através do diário de bordo observou-se que a criança passa a manipular o brinquedo de forma dramática, em que ela extravasava sentimentos, relata situações vivenciadas, diminuindo o medo e a ansiedade. Durante a observação, evidenciou-se um melhor enfrentamento do procedimento após a aplicação do brinquedo terapêutico, sendo notória a mudança de comportamento da criança. Tanto as que estão em tratamento ambulatorial quanto as que estão internadas nas enfermarias.
Concluiu-se que o uso do brinquedo leva a criança a vivenciar momentos prazerosos mediante ao estresse do procedimento, contribuindo para que possa extravasar, expressar sentimentos, aliviar a tensão emocional, criar vínculo com a equipe e, assim, diminuir o medo e a apreensão antes e durante o procedimento, pois permite que ela conheça exatamente o que vai acontecer durante a hospitalização. Sendo satisfatório o resultado de sua aplicação, à medida que possibilitou uma melhora do enfrentamento ao tratamento e resgatou o direito de brincar.

\section{REFERÊNCIAS}

1. Ribeiro CA. O brinquedo terapêutico na assistência à criança hospitalizada: significado da experiência para o aluno de graduação em enfermagem. Rev. Esc. Enf. USP. 1998;32(1):73-9.

2. Ministério da Saúde, Secretaria de Atenção à Saúde, Núcleo Técnico da Política Nacional de Humanização (BR). Humaniza SUS: Documento base para gestores e trabalhadores do SUS. 4. ed. Brasília (DF): MS; 2008.

3. Junqueira MFPS. A mãe, seu filho hospitalizado e o brincar: um relato de experiência. Estud. psicol. 2003 abr;8(1):193-197.

4. Oliveira GF, Dantas FDC, Fonseca PN. O impacto da hospitalização em crianças de 1 a 5 anos de idade. Rev. SBPH. 2004 dez; $7(2): 37-54$.

5. Souza ABG. Brinquedo Terapêutico. In:__ Manual prático de enfermagem pediátrica. São Paulo: Atheneu; 2017. p. 97-108.

6. Gomes CL, Pinheiros MF. A importância do brinquedo terapêutico no cuidar da criança hospitalizada. 54f. [Monografia] Curso de Graduação em Enfermagem - Universidade Mindelo, Cabo Verde, 2013.

7. Paladino CM, Carvalho R, Almeida FA. Brinquedo Terapêutico no Preparo Para a Cirurgia: comportamentos de pré-escolares no período transoperatório. Rev. Esc. Enferm. USP. 2014;48(3):423-9.

8. Souza LPS, et al. O Brinquedo Terapêutico E O Lúdico Na Visão Da Equipe De Enfermagem. J Health Sci Inst. Arquivo Brasileiro da Universidade Estadual de Montes Claros, Minas Gerais, 2012. p. 354-358.

9. Caleffi CC, et al. Contribuição do brinquedo terapêutico estruturado em um modelo de cuidado de enfermagem para crianças hospitalizadas. Rev. Gaúcha Enferm. 2016 mai.;37(2):e58131.

10. Lemos ICS, et al. Brinquedo terapêutico no procedimento de punção venosa: estratégia para reduzir alterações comportamentais. Rev Cuid. 2016;7(1):1163-1170.

11. Dias PLM, Silva IP. A Utilização do Brinquedo durante o Tratamento de Crianças com Câncer: Percepções da Equipe Multidis- ciplinar. Revista Brasileira de Cancerologia 2018;64(3):311-318.

12. Francischinelli AGB, Almeida FA, Fernandes DMSO. Uso rotineiro do brinquedo terapêutico na assistência a crianças hospitalizadas: percepção de enfermeiros. Acta Paul Enferm. 2012;25(1):18-23.

13. Aberastury A. Psicanálise da Criança: teoria e técnica. 8. ed. Porto Alegre: Artes Médicas; 1992.

14. Silva AFF, Santos ECM. A Importância Do Brincar Na Educação Infantil. (Trabalho de Conclusão de Curso) Curso De Especialização - Universidade Federal Rural Do Rio De Janeiro, Mesquita, Rio de Janeiro, 2009.

15. Artilheiro APS, Almeida FA, Chacon JMF. Uso do brinquedo terapêutico no preparo de crianças pré-escolares para quimioterapia ambulatorial. Acta paul. enferm. 2011;24(5):611-616.

16. Cainé SMR. A Utilização do Brinquedo Terapêutico na Preparação de Crianças com Idade Pré escolar para Punção Venosa. (Dissertação) Mestrado em Psicologia da Dor - Instituto Superior de Ciências da Saúde do Norte, Gandra, 2011. p.153.

17. Sossela CR, Sager F. A criança e o brinquedo no contexto hospitalar. Rev. SBPH. 2017 ju.;20(1):17-31.

18. Augusto C, et al. Pesquisa Qualitativa: rigor metodológico no tratamento da teoria dos custos de transação em artigos apresentados nos congressos da Sober (2007-2011). Rev. Econ. Sociol. Rural. 2013 Dec.;51(4):745-764.

19. Ferreira LB, et al. A técnica de observação em estudos de administração. XXXVI Encontro da ANPAD. Rio de Janeiro/RJ - 22 a 26 de setembro de 2012.

20. Silva LF, Cabral IE. O resgate do prazer de brincar da criança com câncer no espaço hospitalar. Rev. Bras. Enferm. 2015 mai./ jun.;68(3).

21. Sposito AMP, et al. $O$ melhor da hospitalização: contribuições do brincar para o enfrentamento da quimioterapia. Av Enferm. 2018;36(3):328-377. 